\title{
KAPPA RECEPTOR MEDIATED OPIOID DEPENDENCE IN RHESUS MONKEYS
}

Debra E. Gmerek and James H. Woods

Department of Pharmacology, M6322 Medical Sclence Building I, University of Michigan Medical School, Ann Arbor, MI 48109-0010

(Received in final form June 17, 1986)

\section{Summary}

The kappa receptor-selective agonist U-50,488 was admin1stered chronically to rhesus monkeys. Tolerance developed to the overt behavioral effects of U-50,488 without crosstolerance to morphine. Withdrawal behaviors produced by deprivation, naloxone or quadazocine administration in $\mathrm{U}-50$, 488-dependent monkeys consisted of hyperactivity, excessive grooming, and yawning. The syndrome was suppressed in a dose-related manner by a kappa agonlst, ethylketazocine, but not by doses of morphine that suppressed its own withdrawal. The mu-selective antagonist, beta-funaltrexamine, at doses which are active in morphine-dependent monkeys, did not precipitate withdrawal in U50, 488-dependent monkeys. Dependence, which is the result of activity at the kappa receptor, was distinct from morphine dependence.

It has long been recognized that chronic administration of some types of oplolds (e.g., nalorphine, pentazocine) results in dependence which is qualitatively unlike morphine dependence $(1,2,3)$. The observation that mild and qualitatively different withdrawal syndromes developed following chronic injections of nalorphine led, in part, to the hypothesis of multiple opioid receptors (1). Only recently, however, have the pharmacologlcal probes become available to permit the characterization of dependence that may occur through the stimulation of kappa receptors specifically.

U-50,488 is a chemically novel oploid, and its kappa-receptor agonist profile may be demonstrated by the following characteristics: (a) it does not suppress withdrawal in morphine-dependent monkeys (4), (b) the compound shares discriminative stimulus characteristics with ethylketazocine, but not with morphine, in rhesus monkeys $(4,5)$, (c) in contrast with morphine, it is not self-administered at rates significantly greater than saline controls in rhesus monkeys (Dr. G. Winger, University of Michigan, personal communication) and rats (5), and (d) it causes diuresis in rats (6) and rhesus monkeys $(5,7)$. The discriminative and diuretic effects of $U-50,488$ are prevented by oplold antagonists as are its antinociceptive actions in a variety of rodent analgesic assays. Nevertheless, in the mouse tail-flick test, 36 times more naloxone was required to inhibit $U-50,488$ to an equivalent degree as morphine (8).

U-50,488 has considerably greater relative affinity for kappa recognition sites than for other opioid binding sites. For example, U-50,488 shows a 256-fold selectivity for kappa over mu or delta binding sites in 
guinea pig brain homogenates (9), whereas dynorphin $A$ (1-13) and ethylketazocine have selectivities for kappa over mu sites of 11.3 and 1.8, respectively (10). Based on the above observations, $U-50,488$ was chosen as having a potential for maintaining kappa receptor-selective stimulation during the administration of $\mathrm{h} I \mathrm{gh}$ doses for an extended perlod of $t$ ime.

Mice and rats treated chronically with $0-50,488$ have not shown signs of dependence upon abrupt withdrawal or naloxone challenge $(5,8,11)$. Similarly. Aceto et al. (12) gave U-50,488 to rhesus monkeys for a period of 45 days and concluded that little morphine-like dependence developed. The question remained, however, if dependence of any type develops. Therefore, in the present investigation, dependence to $0-50,488$ was studied in further detail.

\section{Methods}

Six group-housed rhesus monkeys (Macaca mulatta) (4-5 kg) were given free access to food and fresh water daily, and to fresh frult once weekly. They were trained to receive subcutaneous injections.

U-50, 488 (trans-3,4-d1chloro-N-methyl-N- (2-(1-pyrrolidinyl)-cyclohexyl)benzeneacetamide methanesulfonate, hydrate; Dr. J. Collins, Upjohn Co) was administered s.c. at maximally tolerable (sedative but non-toxic) doses. As tolerance developed the dose was gradually increased from $0.3 \mathrm{mg} / \mathrm{kg} / 6 \mathrm{hrs}$ to $17.5 \mathrm{mg} / \mathrm{kg} / 4 \mathrm{hrs}$ over 135 days (see Results). Testing with beta-funaltrexamine ( $\beta$-FNA, Dr. D. zimmerman, LIlly), $(+)$ and $(-)$ ethylketazocine methanesulfonate (Dr. W. Michne, Sterling-Winthrop), morphine sulfate (Merck), naloxone HCl (Endo), quadazocine (also known as win 44,441, Dr. W. Michne) and U-50,488 occurred at weekly intervals.

On test days, the appearance and behavior of the monkeys was monitored by two experienced observers familiar with the individual animals. Each monkey served as its own control. Injections with test substances began at 10 am: prior to chronic U-50,488 administration, one hour after the last maintenance dose of U-50,488 in non-withdrawn monkeys, or $9 \mathrm{hrs}$ after the last maintenance dose of U-50,488 in withdrawn monkeys. Injections were given every $30 \mathrm{~min}$ such that the total cumulative dose of the test agent increased by $1 / 4-1 / 2$ log-untt with each injection. Muscle relaxation scores were assigned at $30 \mathrm{~min}$ intervals corresponding with arug injections according to a modifled Irwin Scale as described previously $(13,14)$ such that hlgher scores were given to monkeys showing greater amounts of generalized muscle relaxation. For example, monkeys showing pronounced muscle relaxation, slack jaw and shoulder droop were assigned scores of "2". Withdrawa1 behavior was also quantified at $30 \mathrm{~min}$ intervals. The number of bouts of scratching or grooming and the number of yawns, unusual tongue movements and wet-dog shakes displayed by each monkey was counted during a 5-min interval beginning 15-25 min after each injection. These numbers were averaged across all of the monkeys in the group.

\section{$\underline{\text { Results }}$}

The dose of U-50,488 given chronically was increased as the severity and duration of stupor and muscle relaxation decreased. The dose regimen was changed as follows: days $1-6,0.3 \mathrm{mg} / \mathrm{kg} / 6 \mathrm{hrs} ;$ days $7-10,0.56 \mathrm{mg} / \mathrm{kg} / 6 \mathrm{hrs}$; days $11-18,1.0 \mathrm{mg} / \mathrm{kg} / 6 \mathrm{hrs} ;$ days $19-33,3.0 \mathrm{mg} / \mathrm{kg} / 6 \mathrm{hrs} ;$ days $34-54,5.6$ $\mathrm{mg} / \mathrm{kg} / 6 \mathrm{hrs}$; days $55-68,5.6 \mathrm{mg} / \mathrm{kg} / 4 \mathrm{hrs}$; days $69-92,10 \mathrm{mg} / \mathrm{kg} / 4 \mathrm{hrs}$; and days $93-135,17.5 \mathrm{mg} / \mathrm{kg} / 4 \mathrm{hrs}$.

Figure 1 shows the tolerance that developed to U-50,488-induced muscle relaxation. Prior to chronic U-50,488 injections, U-50,488 produced muscle relaxation in a dose-related manner in that with increasing doses, more animals showed higher levels of muscle relaxation. on day 92 of chronic 
U-50,488 administration, $32 \mathrm{mg} / \mathrm{kg} \mathrm{U-50,488}$ did not produce muscle relaxation of scores $\geq$ " 2 " in any of the monkeys, but caused pronounced stupor (1.e., a lack of response to moderate external stimuli) such that higher doses could not be tested. Thus, on day 92 there was a shift down of more than 2.5 log-units relative to day 1 of chronic U-50,488 administration. Cross-tolerance to morphine-induced muscle relaxation did not occur in that there was no change in the morphine dose-effect curve on day 92 compared to the curve obtalned prior to chronic U-50,488 administration.

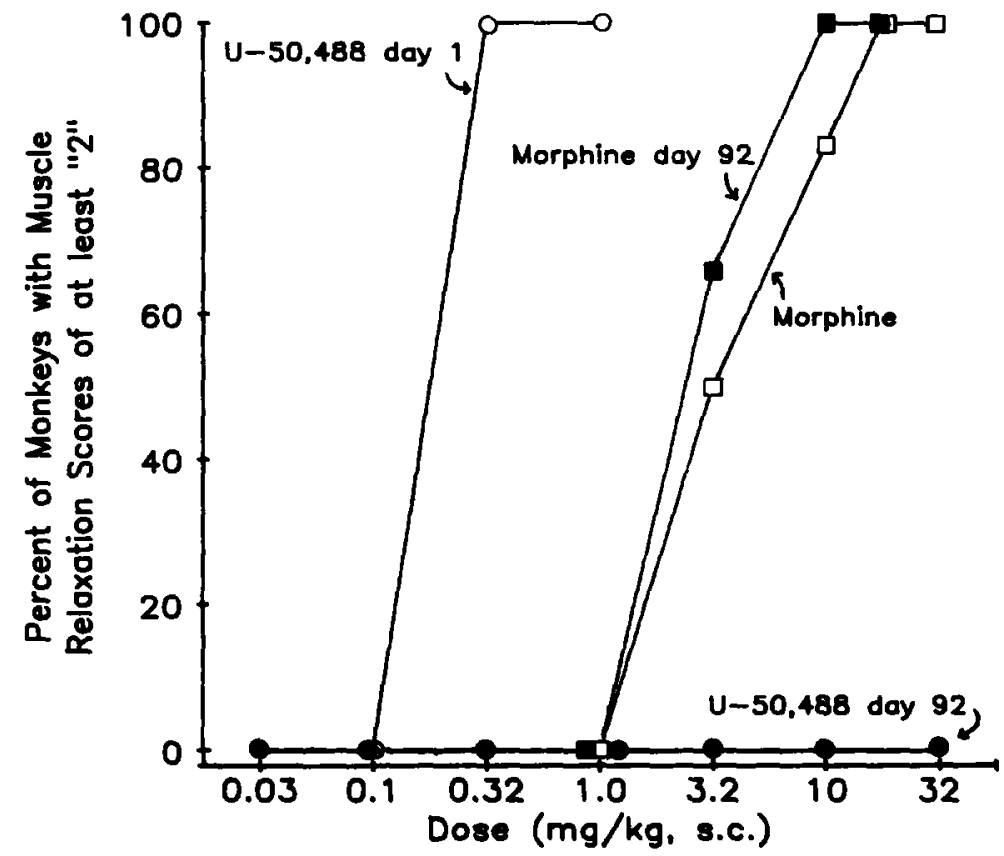

FIG 1

The effect of $U-50,488$ and morphine on muscle relaxation in monkeys receiving chronic injections of $\mathrm{U}-50,488$. U-50,488 was given just prior to the first day of chronic administration (open circles; $n=6$ ) and on day 92 of chronic administration (closed circles; $n=3$ ). Morphine was given one week prior to the chronic administration of $U-50,488$ (open squares; $n=6$ ) and on day 92 of chronic $\mathrm{U}-50,488$ administration (closed squares; $n=3$ ).

At weekly intervals beginning on day 26 of chronic U-50,488 administration, the monkeys were deprived of drug for up to 15 hours. Deprivation resulted in the following behaviors: hyperactivity; excessive grooming that included excessive scratching, grooming of cage-mates, and picking at fingers and toes; and yawning assoclated with unusual tongue movements (e.g., tongue rotated and twisted to the side of the mouth). These behaviors were observed on day 26 of chronic U-50,488 injections but withdrawal signs became more frequent and intense as the duration of U-50,488 administration Increased. 
Dependence reached an apparent steady state following approximately elght weeks of U-50,488 administration. The intensity and number of these behaviors peaked 8-11 hrs after the last injection of U-50,488. There were no signs of irritability or abdominal defense reactions upon handling and palpation which are characteristic of morphine withdrawal.

The monkeys were completely withdrawn from $0-50,488$ after 135 days of chronic administration. Withdrawal signs again peaked following 8-11 hrs of abstinence and were essentially absent by the third $\bar{c}$ ty following drug termination.

Figure 2 shows the suppression (panel a) and precipitation (panel b) of withdrawal in the $U-50,488$-dependent monkeys. The withdrawal signs observid in 9-hr deprived U-50,488-dependent monkeys were suppressed in a dose-related manner by U-50,488. The suppression of withdrawal by etrylketaocine was i] so dose-related and stereoselective in that (-)-ethylketazocine was 10 t'mes more potent than (+)-ethylketazocine in decreasing the number of withdrawal signs. Morphine partially suppressed U-50,488 withdrawal signs only at doses which also caused pronounced stupor and muscle relaxation (1.e., $10 \mathrm{mg} / \mathrm{kg}$; see Figure 1). This dose is sufficient to suppress completely a moderately-severe withdrawal syndrome in monkeys recelving $3 \mathrm{mg} / \mathrm{kg} / 6 \mathrm{hr}$ morphine. Withdrawal behaviors indistinguishable from deprivation-induced withdrawal were precipitated in a dose-related manner by naloxone and quadazocine in the U-50,488-dependent monkeys (panel 2b).
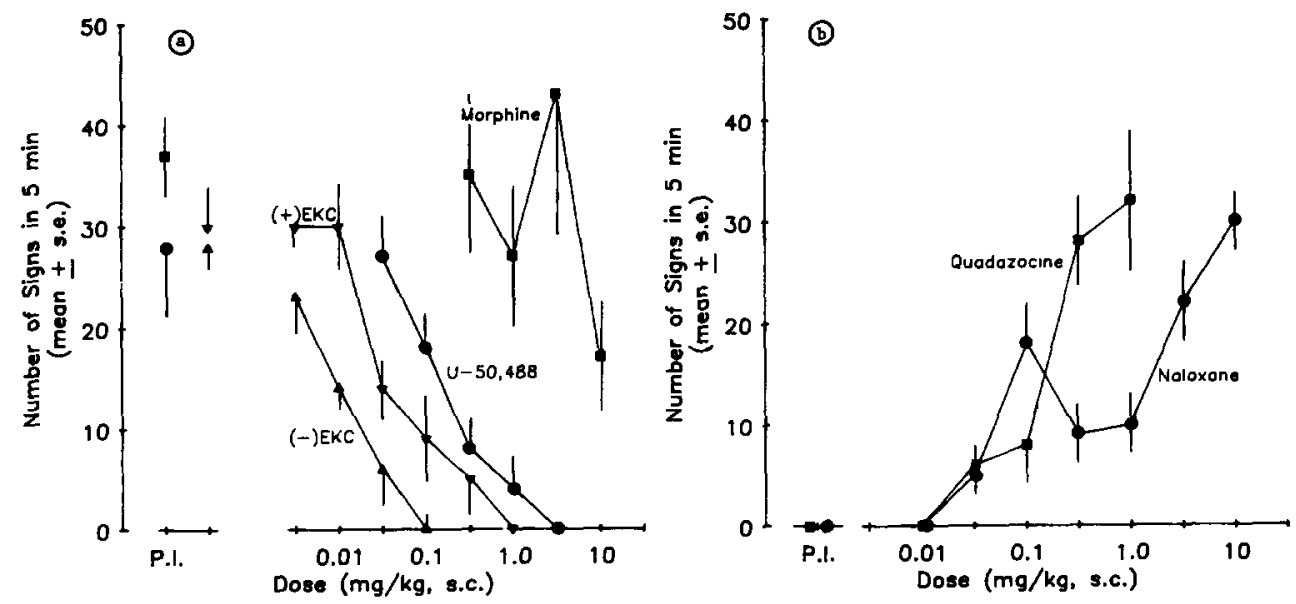

FIG 2

The suppression (a) and precipitation (b) of withdrawal in U-50,488-dependent monkeys. (a) $U-50,488 \quad(n=6)$, morphine $(n=6),(-)$-ethylketazocine (EKC, $n=3$ ) and $(+)$-ethylketazocine $(n=3)$ were given cumulatively beginning 9 hrs after the last maintenance dose of $U-50,488$ on days 89,96 , and 113 of chronic administration, respectively. (b) Naloxone $(n=6)$ and quadazocine $(n=6)$ were given cumulatively beginning one hr after the last maintenance dose of $U-50,488$ on days 75 and 82 of chronic administration, respectively. P.I. = pre-injection.

Beta-funaltrexamine ( $B$-FNA) was given cumulatively at doses of 1-10 $\mathrm{mg} / \mathrm{kg}$ beginning one $\mathrm{hr}$ after the last maintenance dose of $\mathrm{U}-50,488$ (day 62 of chronic administration). B-FNA did not produce any signs of withdrawal, 
although this dose will precipitate a moderately-severe, long-lasting withdrawal syndrome in morphine-dependent monkeys ( $3 \mathrm{mg} / \mathrm{kg} / 6 \mathrm{hrs}$ ) (14).

\section{Discussion}

Chronic administration of U-50,488 resulted in tolerance to its overt behavioral effects without cross-tolerance to morphine. Similarly, in the mouse tall-flick test, multiple injections of U-50,488 over three days resulted in a 26-fold reduction in sensitivity to $U-50,488$ while the sensitivity to morphine changed only slightly (8). Thus, significant tolerance may develop to behavioral properties of $0-50,488$ with little or no cross-tolerance to an equivalent effect produced by morphine.

Deprivation and antagonist-induced abstinence from $U-50,488$ resulted in a distinctive withdrawal syndrome. The signs observed during U-50,488 withdrawal were behaviors that are not normally observed to occur to a significant extent in morphine-dependent monkeys $(3,15)$. Morphine-dependent monkeys undergoing deprivation or antagonist-induced witharawal display behaviors associated with irritabllity and abdominal discomfort: avoldance of all contact with other monkeys, assuming postures which protect the abdomen, extreme irritability to touch, retching and vomiting, and a rigid abdomen when palpated. These signs were never detected in the U-50,488-dependent monkeys, elther during deprivation or following antagonist administration.

Quadazocine was approximately 10 times more potent than naloxone in precipitating $\mathrm{U}-50,488$ withdrawal. In morphine-dependent monkeys, quadazocine was only about three times more potent than naloxone in precipltating withdrawal (unpublished observations). These results are in agreement with studies indicating that quadazocine has less mu-receptor selectivity than naloxone (16). However, these and other potency differences across antagonists are curlous and need to be examined with other behavioral effects. For example, quadazocine has a 30 -fold higher potency in reversing morphine compared to U-50,488 analgesic effects in monkeys (unpublished observations).

An important criterion for inferring a state of dependence is to obtain similar signs both with deprivation of the agonist and with antagonist administration. U-50,488-withdrawal behavior indistiguishable from deprivation-induced withdrawal was precipitated by the opioid antagonists. Moreover, the suppression of U-50,488 withdrawal was stereoselective, with the (-) isomer of ethylketazocine being 10 times more potent than the $(t)$ isomer.

Morphine did not suppress withdrawal in the U-50,488-dependent monkeys at non-sedative doses. At the doses used in the present study, morphine suppresses abstinence associated with 1 ts chronic administration $(3 \mathrm{mg} / \mathrm{kg} / 6$ hrs). Conversely, U-50,488 suppresses withdrawal signs in morphine-dependent monkeys only at doses which also produce severe stupor (4). The mu-selective antagonist $\beta-F N A$ (17) did not produce any withdrawal signs in the U-50,488dependent monkeys up to a dose of $10 \mathrm{mg} / \mathrm{kg}$. This dose of B-FNA precipitates withdrawal equivalent to 14-hr abstinence in morphine-dependent monkeys (14). These data indicate that the precipltation and suppression of U-50,488 withdrawal may be selectively produced by antagonists and agonists, known in other assay systems, to be opioid receptor selective. Given these results, together with the considerable in vitro selectivity of $U-50,488$, it is suggested that this form of dependence is produced by activation of the kappa receptor. 


\section{Acknowledgments}

We thank Dr. James Collins (The Upjohn Company, Kalamazoo, MI) for the generous supply of U-50,488; and Mel Dickerson and Fred Adams for their excellent technical assistance. This work was supported by USPHS grant DA 00254.

\section{References}

i. W.R. MARTIN, Pharmacol. Rev. 19 463-521 (1967).

2. J.H. WOODS, C.B. SMITH, F. MEDZIHRADSKY and H.H. SWAIN, Mechanisms of Pain and Analgesic Compounds, pp. 429-445, Raven Press, New York, (1979).

3. J.H. WOODS and D.E. GMEREK, Drug. Alc. Dependence 14 233-247 (1985).

4. J.L. KATZ, J.H. WOODS, G.D. WINGER and A.E. JACOBSON, Life Sci. 31 2375-2378 (1982).

5. A.H. TANG and R.J. COLLINS, Psychopharmacology 85 309-314 (1985).

6. J.D. LEANDER, Eur. J. Pharmacol. 86 467-470 (1983).

7. D.E. GMEREK and J.H. WOODS, Pharmacologist 25208 (1984).

8. P.F. VONVOIGTLANDER, R.A. LAHTI and J.H. LUDENS, J. Pharmacol. Exp. Ther. 224 7-13 (1983).

9. R.A. LAHTI, M.M. MICKELSON, J.M. MCCALL and P.F. VONVOIGTLANDER, Eur. J. Pharmacol. 109 281-284 (1985).

10. I.F. JAMES and A. GOLDSTEIN, Mol. Pharmacol. 25 337-342 (1984).

i1. A. COWAN, H.I. MOSBERG, F. PORRECA and X.Z. ZHU, Br. J. Pharmacol. 85 294P (1985).

12. M.D. ACETO, L.S. HARRIS, W.L. DEWEY and E.L. MAY, NIDA Research Monograph 27, pp. 330-355, U.s. Government Printing Office, Washington, DC (1979).

13. S. IRWIN, Doctoral Dissertation, University of Michigan (1953).

14. D.E. GMEREK and J.H. WOODS, J. Pharmacol. Exp. Ther. 235 296-301 (1985).

15. J.E. VILLARREAL, Agonist and Antagonist Actions of Narcotic Analgesic Drugs, pp. 73-93, University Park Press, Baltimore (1973).

16. S.J. WARD, A.K. PIERSON and W.F. MICHNE, Life Sc1. 33 (Suppl. 1) 303 (1983).

17. P.S. PORTOGHESE, D.L. LARSON, L.M. SAYRE, D.S. FRIES and A.E. TAKEMORI, J. Med. Chem. 23 233-234 (1980). 